\title{
Research Paper \\ The requirements of technological change according to the dimensions of green production: Survey of the State Company for Northern Cement / Badoush
}

Journal of

\section{TANMIYAT AL- RAFIDAIN}

\section{(TANRA)}

A scientific, quarterly, international, open access, and peer-reviewed journal

Vol. 40, No. 130

June 2021

(C) University of Mosul | College of Administration and Economics, Mosul, Iraq.

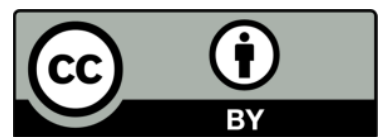

TANRA retains the copyright of published articles, which is released under a "Creative Commons Attribution License for CC-BY-4.0" enabling the unrestricted use, distribution, and reproduction of an article in any medium, provided that the original work is properly cited.

Citation: Youssef, Ahmed Abdul Karim Al-JaliliM.Alaa Haseeb, (2021)."The requirements of technological change according to the dimensions of green production: Survey of the State Company for Northern Cement / Badoush". TANMIYAT ALRAFIDAIN, 40 (130), 258 -276, https://doi.org/10.33899/tanra.20 20.128368 .1055

P-ISSN: 1609-591X

e-ISSN: 2664-276X

tanmiyat.mosuljournals.com

\section{Ahmed Abdul Karim Youssef ${ }^{\text {1: }}$ Alaa Haseeb Al-Jalili ${ }^{2}$}

${ }_{1 \& 2}$ College of Management and Economics - Industrial Management University of Mosul / Iraq

Corresponding author: Ahmed Abdul Karim Youssef. Presidency University of Mosul. University of Mosul, abdulkareemahmed278@gmail.com.

DOI: https://doi.org/10.33899/tanra.2020.128368.1055

Article History: Received: 21/8/2020; Revised: 28/9/2020; Accepted: 5/10/2020; Published: 1/6/2021.

\section{Abstract}

The current research on the implications of the philosophy of its objectives sought to identify the requirements of technological change according to the dimensions of green production through an exploratory study in the Badoush cement factory, in addition to identifying the correlation and influence relationships between the requirements of technological change and the dimensions of green production in the Badoush cement plant.

The two researchers sought to include the research variables within a holistic framework, and to this end, the research problem was formulated with a set of questions summarized as follows:

1. What is the level of the direction of the laboratory in question to apply a technological change to achieve green production in the sector in which it operates?

2. Is there a significant correlation between technological change and green production in the laboratory under consideration?

3. Is there a significant influence relationship between technological change and green production in the laboratory under investigation? The research reached a set of conclusions, the most important of which is the existence of a positive significant correlation between the requirements of technological change and the dimensions of green production at the level of the laboratory under consideration, as well as the existence of a positive significant effect relationship between the requirements of technological change and the dimensions of green production at the level of the laboratory under consideration.

Keywords

Change, technological change, green production Methodology. 
ورقة بحثية

متطلبات التّغييز التّكنولوجي على وفث أبعاد الإنتاج الأخضر:

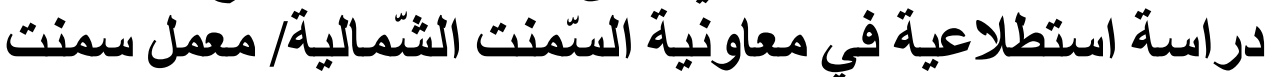

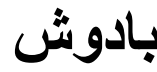

الباحث أحمد عبد الكريم يوسف ' ؛؛ أ.م.د. الاء حسيب الجليلي'

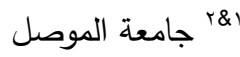

المؤلف المراسل الباحث احمد عبد الكريم يوسف، ، جامعة الموصل، الموصل، العراق، abdulkareemahmed278@gmail.com.

DOI: https://doi.org/10.33899/tanra.2020.128368.1055

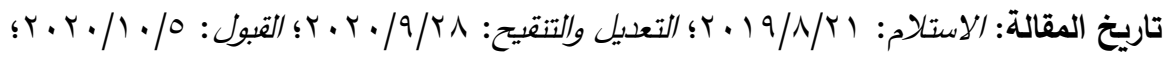

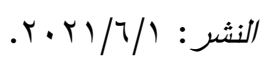

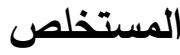

سعى البحث الحالي في مضامين فلسفة أهدافه إلى التّعرف على متطلبات التّغيير التّكنولوجي وفق أبعاد

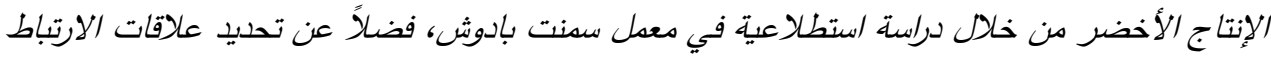

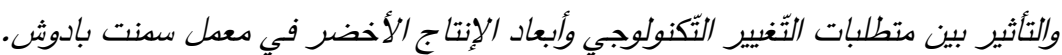
وسعى الباحثان إلى تضعين متغيرات البحث ضمن إطار شعولي، وتحقيقا لهذا الغرض تم صياغة

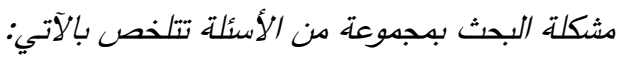

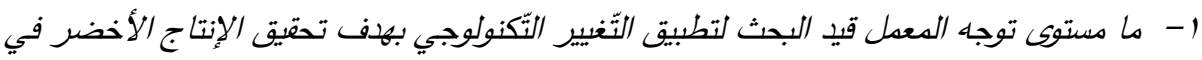

$$
\text { القطاع الذي تعدل فيه؟ }
$$

r- هل توجد علاقة ارتباط معنوية بين التّغيير التّكنولوجي والإنتاج الأخضر في الدعل قيد البحث؟

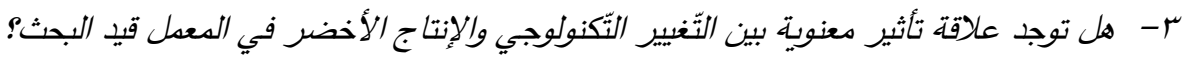

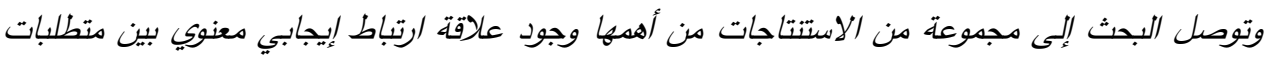
التّغيير التّكنولوجي وأبعاد الإنتاج الأخضر على مستوى المعدل قيد البحث، وكذلك وجود علاقة تأثير إيجابي معنوي بين متطلبات التّغيير التَكنولوجي وأبعاد الإنتاج الأخضر على مستوى الدعدل قيد البحث. الكلمات الرئيسة الثّغيير، الثّغيير الثّكنولوجي، الإنتاج الأخضر

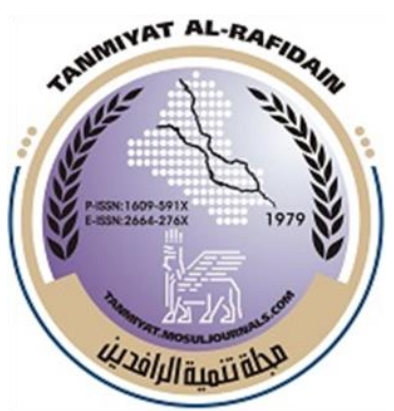

هبلة

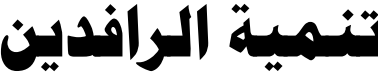

(TANRA) دولية، مفتوحة الوصول، محكمة.

$$
\begin{aligned}
& \text { المجلد (••)، العدد (•r ())، } \\
& \text { حزيران (T.r }
\end{aligned}
$$

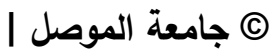
كلية الإدارة والاقتصاد، الموصل، العراق.

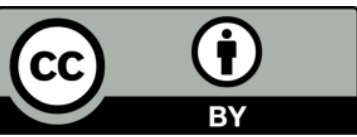

تحتفظ (TANRA) بحقوق الطبع والنشر للمقالات

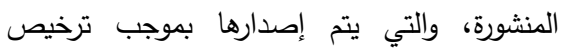

\lrcorner (Creative Commons Attribution) (CC-BY-4.0)

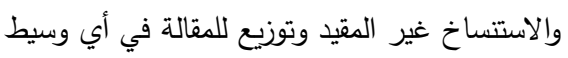
نقل، بشرط اقتباس العمل الأصلي بثكل صحيح. الاقتباس:يوسف،احمد

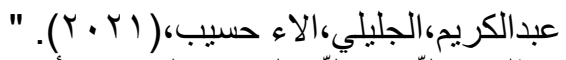

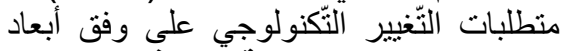

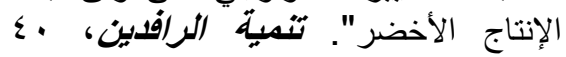

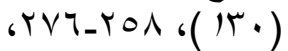
https://doi.org/10.33899/tanra.20 20.128368 .1055

P-ISSN: 1609-591X

e-ISSN: 2664-276X

tanmiyat.mosuljournals.com 
تواجه الثركات اليوم موجة من التّيّيرات المختلفة، وجوهر هذه التّغييرات في بيئة شركات اليوم نابعة

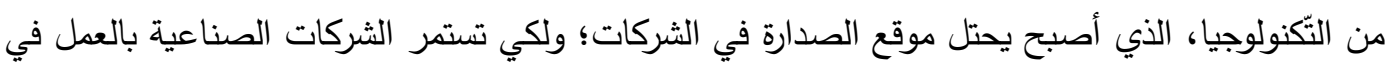
بيئة تتميز بالمنافسة الثديدة بين الثركات المتتافسة، يجب أن تستخدم هذه الشركات نهجاً حديثاً يتسم بالمرونة

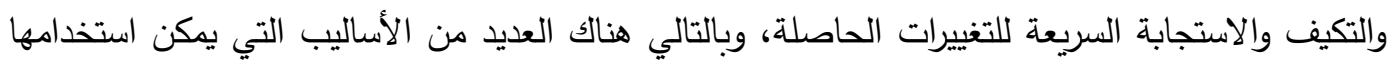

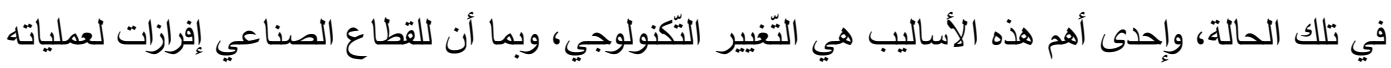
الإنتاجية التي يمكن وصفها في بعض الأحيان بأنها قاسية تجاه البيئة واستتزاف مواردها الطبيعية، مدّا أستدعى ذلك ضرورة البحث عن مدخل مهم تتمثل بالإنتاج الأخضر بوصفه صديقاً للبيئة.

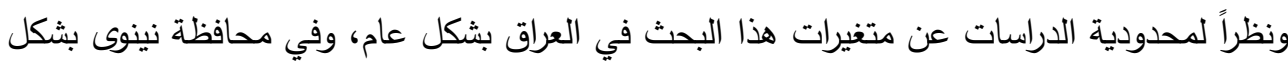
خاص، فقد وجد من المناسب دراسة هذين المتغيرين ضمن إطار شمولي، إذ تضمن البحث المباحث الآتية:

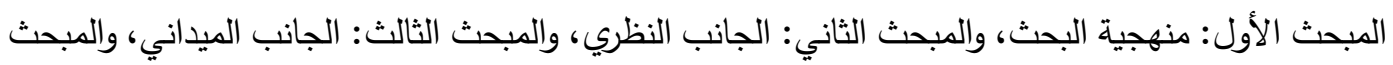
الرابع: الاستنتاجات والتوصيات. المبحث الأول: منهجية البحث يتضمن هذا المبحث المنهجية المستخدمة في البحث وفق المحاور الآتية:

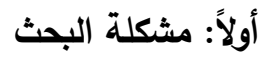

تمثل مشكلة البحث حاجة يراد إثباعها، وبالمقابل أهيّة هذه الحاجة هي التي تقوم بتبرير سبر غورها؛

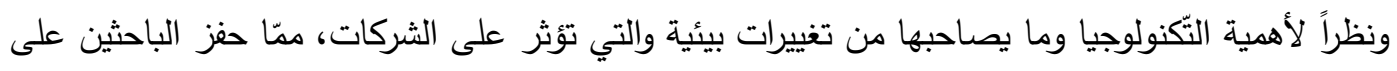

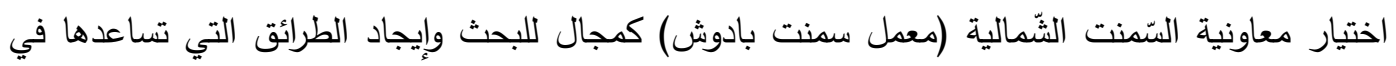

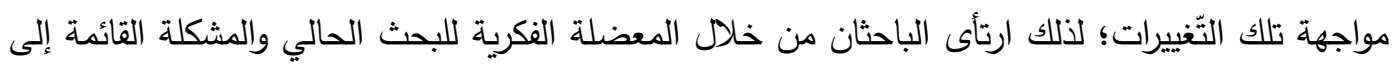
التقارب بين المحتوى الفكري والواقع العملي في صياغة مجموعة من التساؤلات والتي تعكس مشكلة البحث

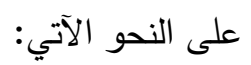
ا ـ ما مدى تصوّر المديرين في معمل سمنت بادوش عن التّغير التكنولوجي والإنتاج الأخضر؟

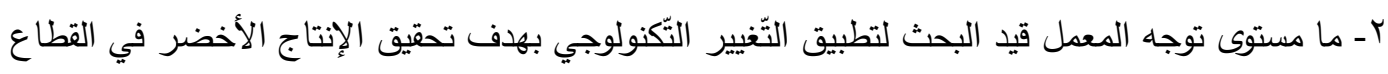
الذي تعمل فيه؟ r- ما مستوى فاعلية الأساليب التّكنولوجية في الإنتاج الأخضر للمعمل قيد البحث؟

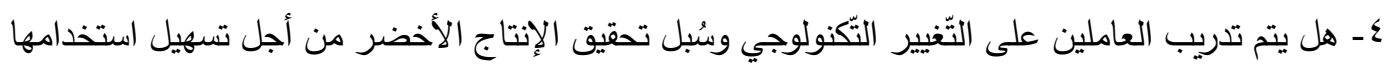
لتحقيق أهداف المعمل قيد البحث؟ لثبن

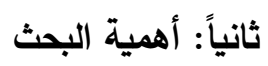

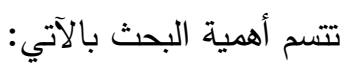


1- تقديم منهجيّة نظريّة تساعد المعل قيد البحث على فهم كيفيّة اعتماد التّغيير التّكنولوجي في تحقيق

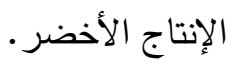

r- تحديد واقع التّغيير التكنولوجي وأهميّته للمنظمة قيد البحث، وموقفها من هذا الموضوع الحيوي والأساليب

$$
\text { والأدوات التي تستخدمها لتحقيق الإنتاج الأخضر . }
$$

ب- تمثل أهمية هذه البحث إسهاماً في تسليط الضوء على موضوع مهم وحيوي، هو التّغيير التكنولوجي؛ لأنه

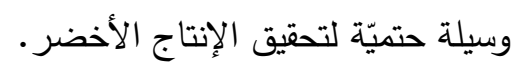
ع - قلة تطبيق مدخل التّغيير التكنولوجي، وانعكاس ذلك في تحقيق مدخل الإنتاج الأخضر للشركات العراقيّة عامةً، وللمعمل قيد البحث خاصةً. ثالثاً: أهداف البحث

$$
\text { يمكن تحديد أهداف البحث بالآتي: البحث: ألتاف }
$$

1- مساعدة المعمل قيد البحث على تطبيق الإطار العملي لمتغيّرات البحث لهعرفة مستوى توجهها لتطبيق

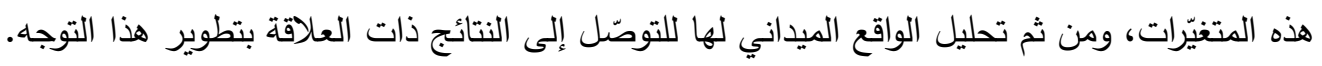

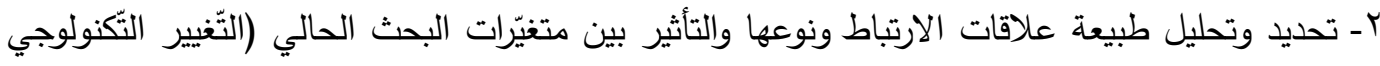
والإنتاج الأخضر ) للتأكد من صحّة العلاقات السبيّة والمنطقيّة بين هذه المتيّيّرات.
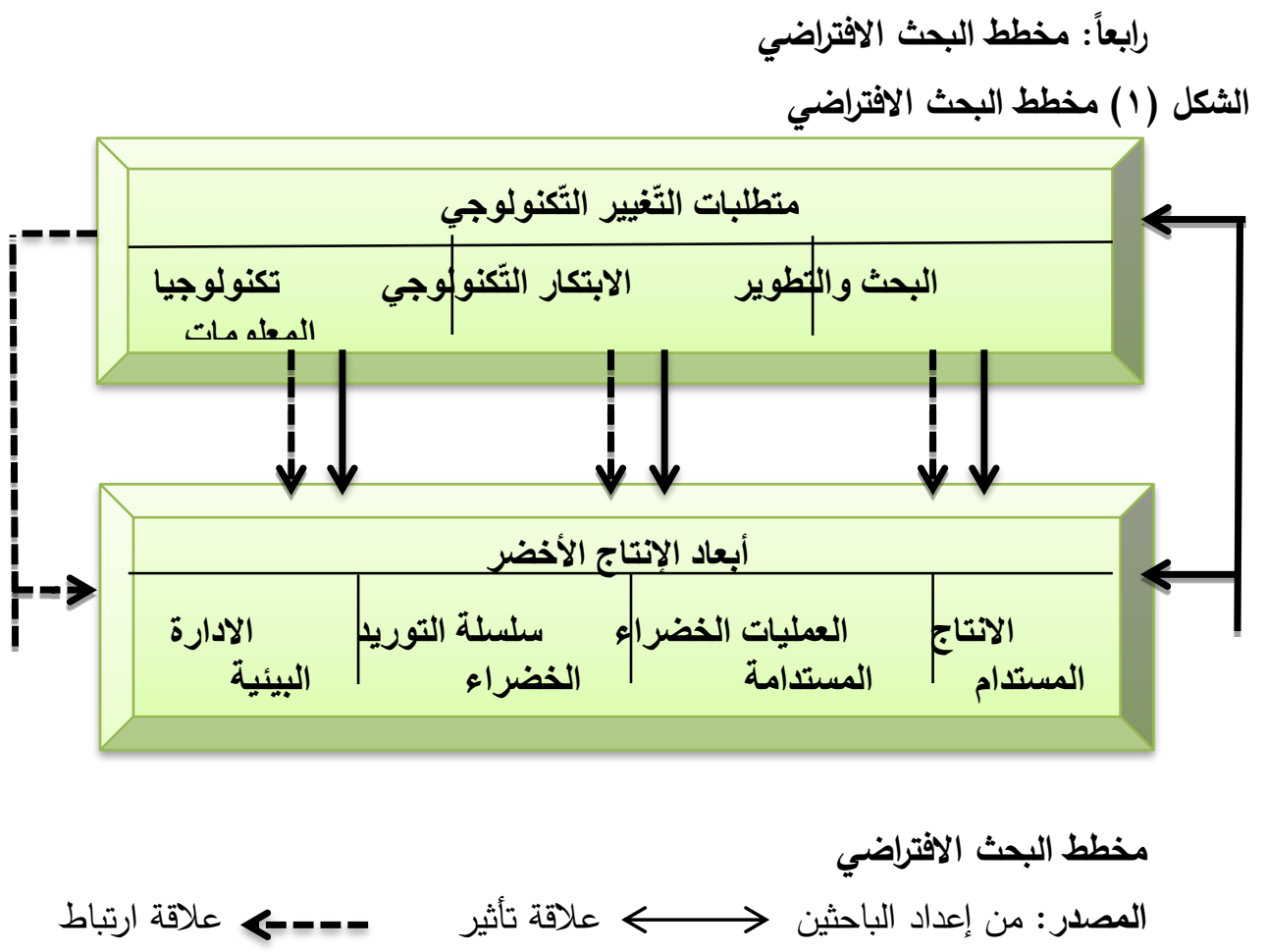


$$
\text { خامساً: فرضيات البحث }
$$

أ-الفرضيّة الرئيسة الأولى (فرضية الارتباط):

هناك علاقة ارتباط ذات دلالة معنويّة بين منطلبات التّغيير التّكنولوجي مجتمعةً وأبعاد الإنتاج الأخضر الأبر

مجتمعةً في المعمل قيد البحث، ويتفرّع من الفرضيّة الرئيسة الأولى الفرضيّة الفرعيّة الآتية:

هناك علاقة ارتباط ذات دلالة معنويّة بين كل متطلب من متطلبات التّغيير التكنولوجي وأبعاد الإنتاج

الأخضر مجتمعةً في المعمل قيد البحث.

ب-الفرضيّة الرئيسة الثانية (فرضية الأثر):

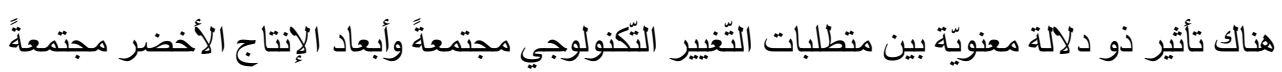

في المعمل قيد البحث، ويتقرّع من الفرضيّة الرئيسة الثانية الفرضيّة الفرعيّة الآتية:

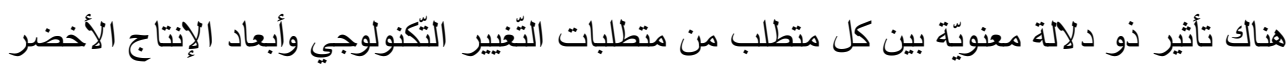

$$
\text { سجتمعةً في المعمل قيد البحث. }
$$

اعتمد الباحثان على المنهج الوصفي والتحليلي في كتابة الجانبين النظري والعملي وصولاً إلى ماتى

$$
\text { سابعاً: حدود البحثتاجات والمقترحات الخاصة بالبحث الحالي. }
$$

اشتملت حدود البحث على الحدود الزمانية والمكانية، فضلاً عن الحدود البشرية وعلى النحو الآتي:

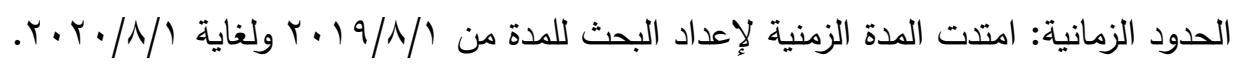

الحدود المكانية: أُختير معمل سمنت بادوش الواقعة في محافظة نينوى ميداناً للبحث الحالي.

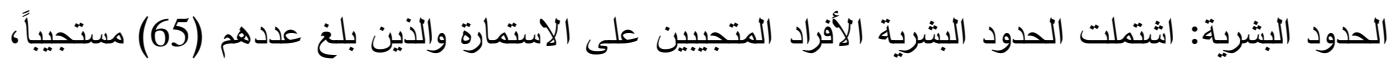

$$
\text { ثامناً: أساليب جمع البينة البحث العاملين في المعمل المبحوث. }
$$

ولفهم أهداف البحث المحددة والحصول على البيانات، والمعلومات المطلوبة اعتمد الباحثان على البى

أدوات بحثية عديدة والتي يمكن تصنيفها على جانبين هما:

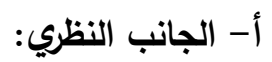

وثق البحث الحالي في جانبها النظري على أساس مجموعة من المصادر والمراجع العربية والأجنبية، إذ تمثلز المصادر بالكتب والمجلات العلمية والبحوث التي تصدرها المنظمات الرائدة في مجالات الأعمال، وكذلك الرسائل والأطاريح الجامعية، فضلاً عن مواقع الثبكة العنكبوتية (الانترنت).

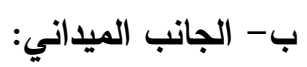

وثق الباحثان المقابلات الثخصية مع مقر الشركة والمدير العام لمعمل سمنت بادوش، وكذلك مدير الإدارة ومدير قسم البيئة بالإضافة إلى مدير قسم الجودة وقسم التدريب لغرض الحصول التصني على البيانات 
والمعلومات، فضلاً عن استمارة الاستبيان التي تستخدم أداة رئيسة لجمع البيانات وقياس أبعاد البحث، وعرضت على المتخصصين في هذا المجال، وقد تضمنت فقرات الاستبانة في تصميمها وفق مقياس (ليكرت الخماسي)، وتم إعداد الفقرات من خلال الدراسات المختصة في هذا المجال.

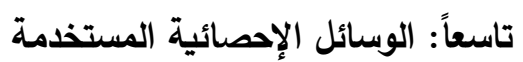

تم اختيار مجموعة من الأدوات الإحصائية هي البرنامج الإحصائي (Excel) وكذلك الحزمة

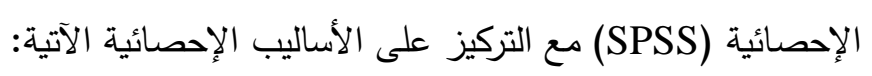

1- الأدوات التي تستخدم في وصف متغيرات البحث وتثخيصها والتي تتمثل بالتكرارات، والنسب المئوية،

$$
\text { والأوساط الحسابية، والانحرافات المعيارية. }
$$

ץ-أدوات اختبار مخطط البحث وفرضياتها، إذ اعتمد الباحثان على أدوات عديدة أسهمت في الاختبار قياس الاستجابة، معامل الارتباط الخطي (Spearman)، اختبار F، اختبار T)، معامل ألفا كرونباخ (Clpha)

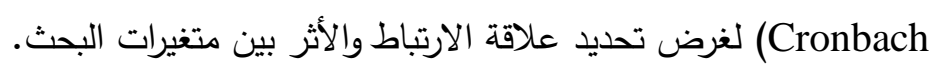
عاشراً: اختبار ثبات الاستبانة

لغرض التحقق من صدق الاستبيان المعتمد في البحث الحالي وإثباته كإجراء موثوق باه تم استخدام

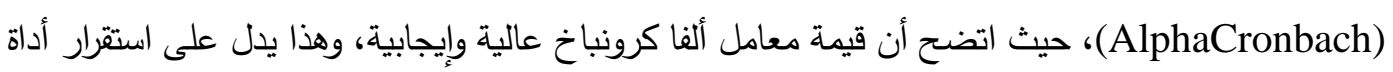
الاستبيان، وقيمة معامل ألفا كرونباخ سجلت (A4.7)، (Alp) على المستوى الكلي للمتغيرات. المبحث الثاني: الجانب النظري المحور الأول: التّفيير التّنولوجي :لتبانب يتضمن هذا المحور الفقرات الآتية:

أولاً: مفهوم التّغيير التّكنولوجي: إنّ التّيير التّكنولوجي هو أحد أهم العوامل المحددة لزيادة سريعة في حجم

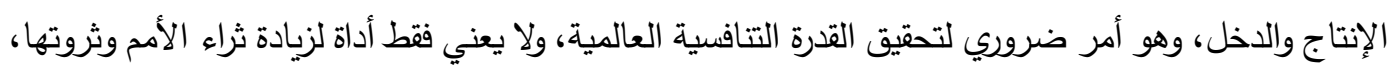

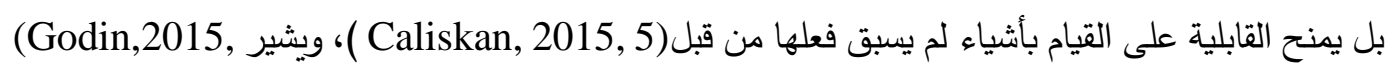

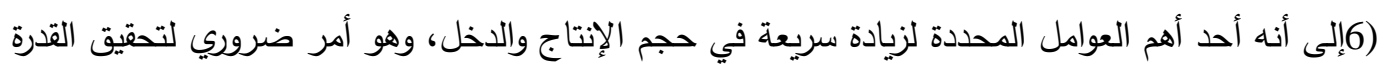

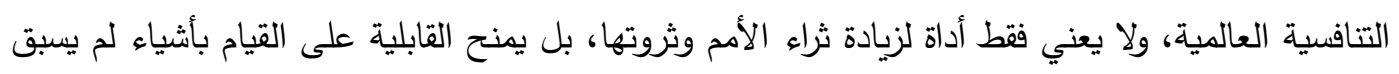

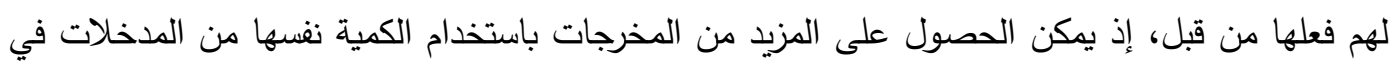
أي عملية إنتاج سيؤدي هذا بالتأكيد إلى تحقيق وفورات في قوة العمل ورأس المال، في حين أشار (Alsamydai, 2014, 204)

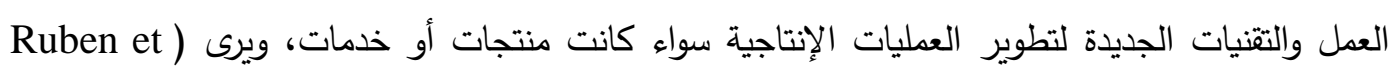
(al.,2019, 5 تبني تقنيات جديدة لتطوير العملية الحالية أو تقديم عمليات جديدة لم يتم فعلها حتى الآن. 
اتساقاً مع ما تقدّم، يُقدم الباحثان مفهومًا إجرائيًا للتغيير التكنولوجي على أنه عملية تبني مشروعات،

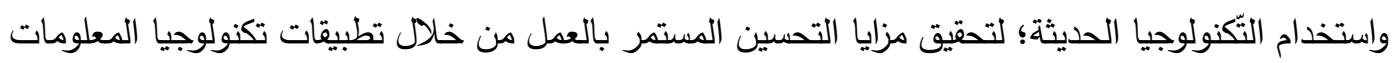
المختلفة، والتي تسهم إلى حد كبير في الاستثمار الأفضل لموارد المعمل المختلفة. ثانياً: عوامل نجاح التّفيير التّنولوجي ولتي هناك خمسة عوامل لنجاح التّغيير التكنولوجي لأية منظمة إذا ما أرادت إجراء تغييرات تكنولوجية على عمالها، سواء كانت منظمة صغيرة أو كبيرة، وعلى النحو الآتي (daft ، 2010، 415):

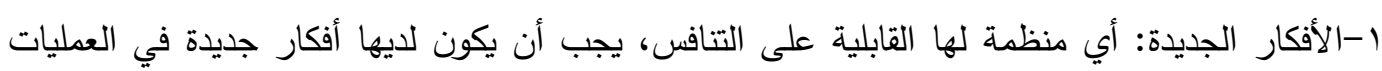

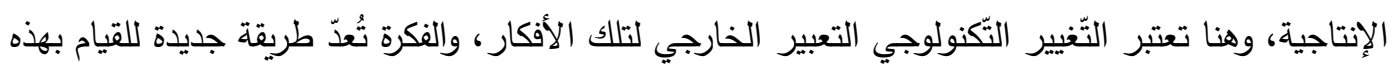
الأمور ، إذ إن التّغيير في المنتج أو الخدمة الجديدة يمكن أن يتأتى من الأفكار من داخل المعمل أو خارجها.

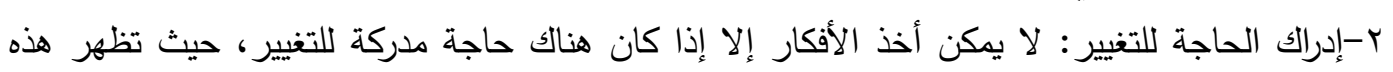

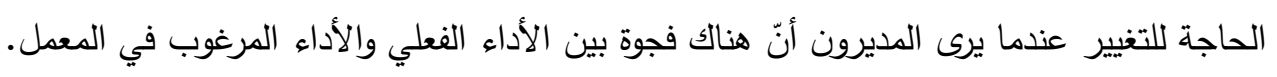

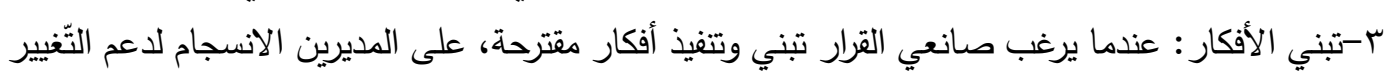

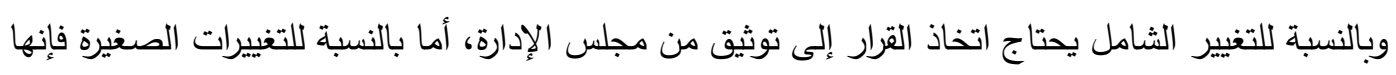
تحتاج إلى موافقة الإدارة الوسطى. ع-تتفيذ الأفكار : يقوم العاملون في المعمل بتتفيذ أفكار جديدة أو تقنية جديدة أو سلوك جديد، حيث يُعدّ الوند

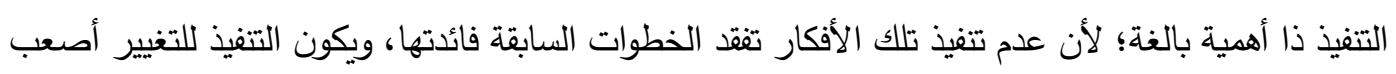
مرحلة؛ نتيجة عدم وجود تغيير فعلي لكي يوظف العاملون الفكرة الجديدة. ه-توفر الموارد اللازمة: إذ يتطلب التّغيير توافر حافز معنوي للعاملين لغرض التّنغيير ، وكذلك يتطلب توافر

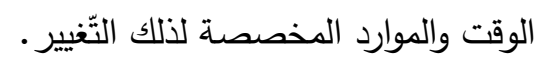
ثالثاً: متطلبات التّيير التّكنولوجي تباينت وجهات نظر الباحثين حول متطلبات التّغيير التّنولوجي كل بحسب دراساته عنه إلا أن العديد

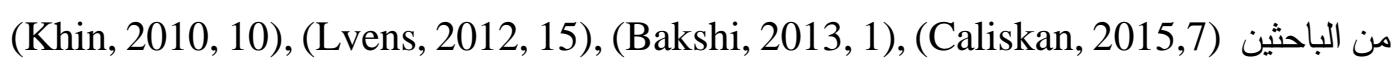
(Nikoloski, 2016, 5) (Ulrich \& Jordi, 2018, 7) البحث والتطوير ، الابتكار التّنولوجي، تكنولوجيا المعلومات)، ويمكن توضيح كل متطلب بثكل موجز وعلى النحو الآتي: 1-متطلب البحث والتطوير : يشير (Ebhota, 2014, 187-188) إلى أن كافة الدجهودات التي تتضمن تحويل المعرفة المصادق عليها إلى حلول فنية أو أساليب وطرائق الإنتاج المختلفة أو منتجات، إذ تلتركز

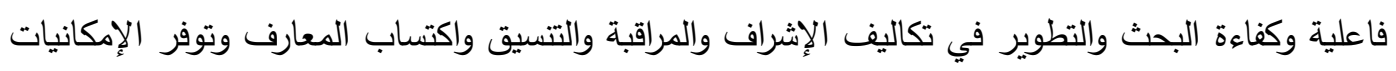
المادية والتكنولوجية وربطها في مستوى إداري مسؤول؛ وذلك لتقييم فاعليتها وكفاءة أدائها. 
r-متطلب الابتكار التكنولولجي: يشير (Stoever \& Weche, 2018,7) إلى أن العملية التي تقوم بها المنظمات بتصميم وإنتاج سلع وخدمات جديدة، من خلال وضع جداول زمنية لأنشطة، مثل تطبيق تكنولوجيات وتتفيذ نظم إنتاج جديدة، وتحسين نوعية الإنتاج، واستكثاف منتج جديد، بما في ذلك سلسلة من الأنشطة

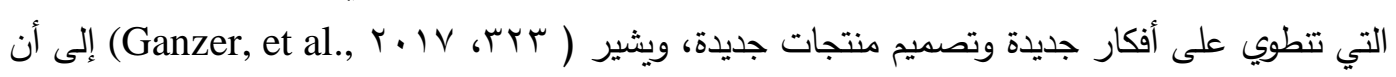

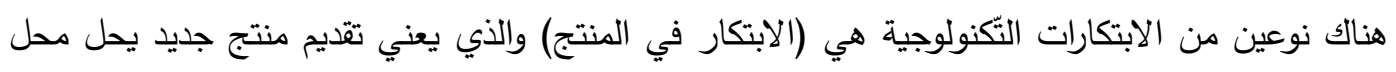
منتج موجود بالفعل بهدف، ويشمل تقديم منتج جديد لم يتم تسويقه وبيعه من قبل، أما (الابتكار في العملية)

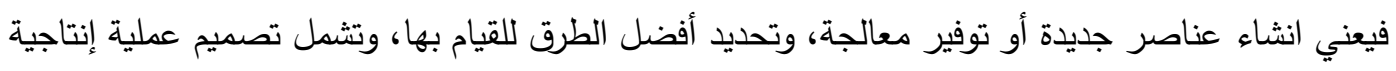

$$
\text { بشكل يحسن من نوعية وكمية الإنتاج. }
$$

ب-متطلب تكنولوجيا المعلومات: يثير ( Abraham, 2016, 25$)$ إلى أن تكنولوجيا المعلومات تعني إتاحة تمكين مديري المنظمات من القابلية على اتخاذ القرارات، والقيام بتحليلها من خلال البيانات المتوافرة لديها،

$$
\text { والتي تتميز بسهولة الوصول للبيانات ومشاركتها بين العاملين. }
$$
المحور الثاني: الإنتاج الأخضر يتضمن هذا المحور الفقرات الآتية: أولاً: مفهوم الإنتاج الأخضر: يُعدّ الإنتاج الأخضر نظامًا حديثًا يوفر منظوراً جديداً عن البيئة وكفاءة المواد

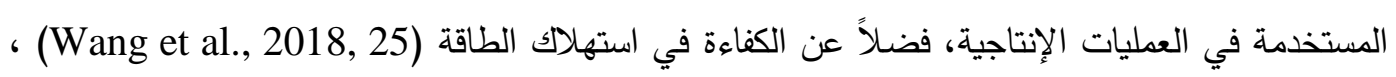

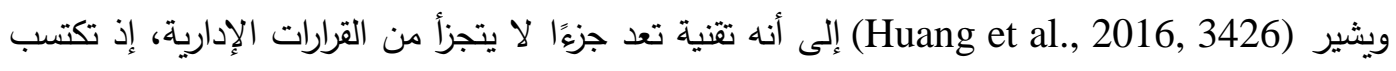
أهمية داخل المنظمات ليس بزيادة إنتاجية المنظمة والتقليل من هدر الإنتاج فحسب، بل تلب تحسين أعمال

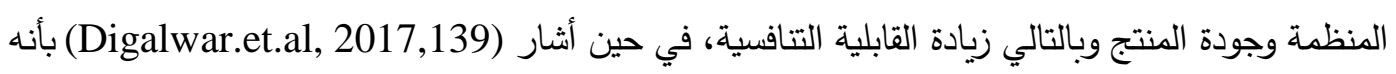
نظام حديث في الإنتاج يقوم على أساس الحد من الآثار البيئية في جميع مراحل العملية الإنتاجية، بدئًا من فن فئن

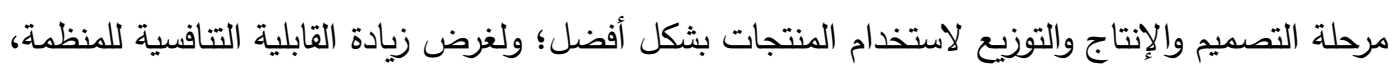

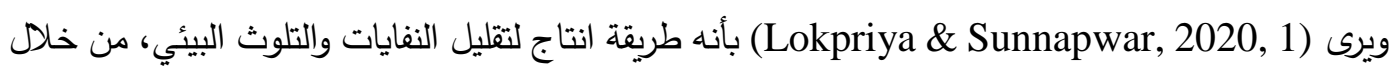
تحسين الاداء البيئي لعمليات الإنتاج، عن طريق أفضل الممارسات، والسعي للقضاء على عمليات توليد النفايات.

إتساقاً ممّا سبق يقدّم الباحثان مفهوماً إجرائياً للإنتاج الأخضر باعتباره نظاماً للعمليات الإنتاجية لإنتاج

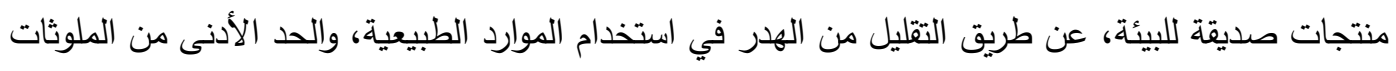

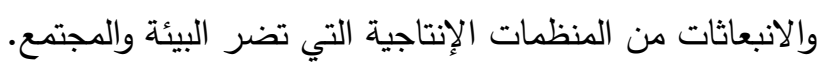
ثانياً: منهجية التحول إلى الإنتاج الأخضر الأنتاجية

إن منهجية التحول إلى الإنتاج الأخضر لحل مشكلات الملوثات والنفايات الصناعية، يتم من خلال

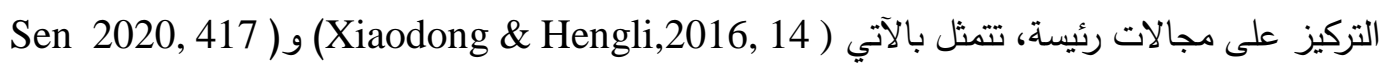
:(\& Ruchi, 
1-التصميم الأخضر : أي ينبغي أن يضع المنتجات الصناعية في الاعتبار كلياً، مثل جودة المنتج والعلاقة

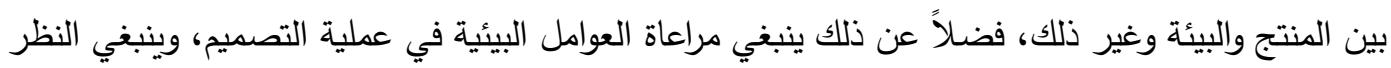

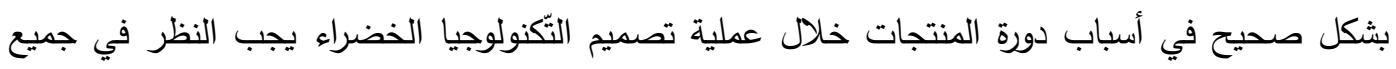
وظائف المنتج، وكذلك التحسينات المعقولة في عملية التصميم، بحيث تفي المنتجات بنتائج تحسين المنتج.

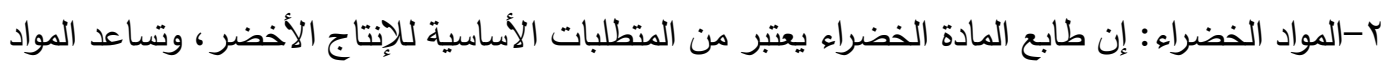

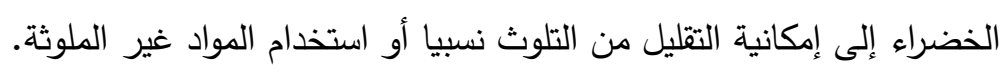

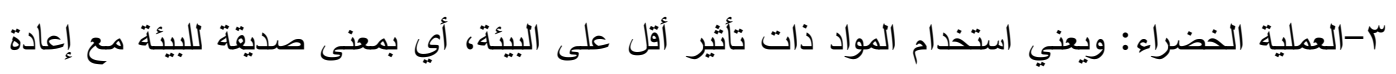
استخدام الموارد واستخدام تكنولوجيا إعادة التدوير بعقلانية وكفاءة؛ من أجل تحقيق هدف تحسين ميزات الجئي المنتجات ع-التكنولوجيا الخضراء: وتشير إلى التكنولوجيا الموفرة للطاقة والحد من التلوث البيئي وإنتاج منتجات تكون صديقة للبيئة، وينبغي أيضاً النظر في كيفية الحد من استخدام المواد وكيفية الحد من التأثير على البيئة. ثالثاً: أبعاد الإنتاج الأخضر تباينت وجهات نظر الباحثين حول أبعاد الإنتاج الأخضر كل بحسب دراساته عنه، إلا أن العديد من

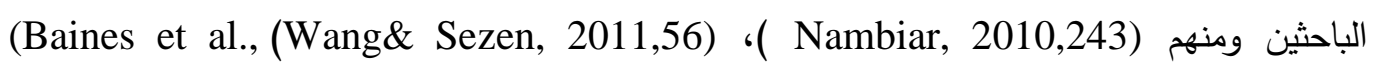
(Richard, 2016,86)، (Zeya, 2015,6) 2012,34)

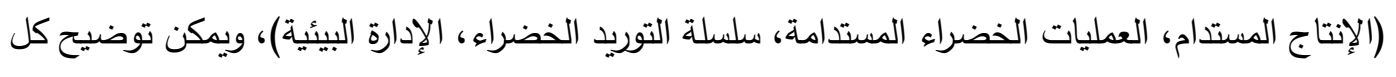
بعد بثكل موجز وعلى النحو الآتي: ا-بعد الانتاج المستدام يشير (Machado et al., 2019,6) إلى أن الانتاج المستدام هو نظام متمم للعمليات والأنظمة الانتاجية الأخرى التي لها القابلية على إنتاج منتجات وخدمات ذات جودة عالية، والتي لتي تستخدم موارد أقل (الطاقة والمواد) وأكثر استدامة، وتكون آمنة للعاملين والمجتمعات المحلية المحيطة به الهاتهات

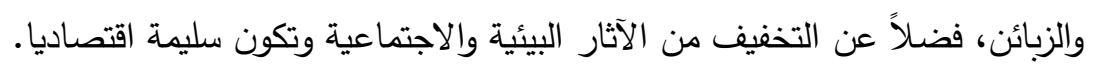
r-بعد العمليات الخضراء المستدامة يثير (Aneirson et al., 2020, 9) إلى أنها عملية استخدام عمليات صديقة للبيئة، وتحسين الكفاءة التثغيلية، وخفض الكلف؛ نتيجة زيادة كلف الطاقة والمواد الاولية وزيادة وعي

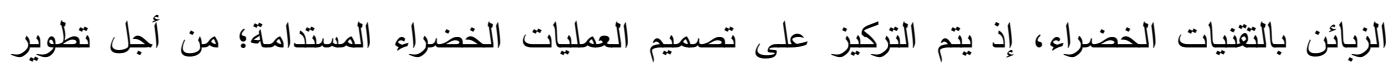

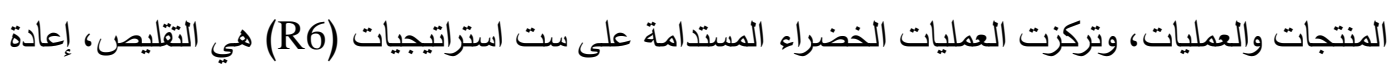
التدوير ، إعادة الاستخدام، الاسترجاع، إعادة التصنيع، إعادة التصميم ( 0 ( ؛ , Ansari , 2016). ب-بعد سلسلة التوريد الخضراء يثير (Petljak et al., 2018, 3) إلى أنها عملية دمج التنكير البيئي في

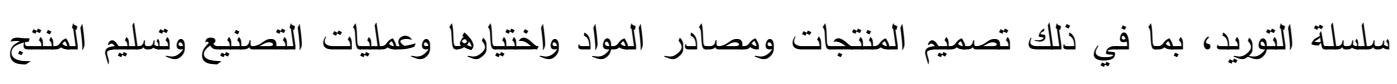

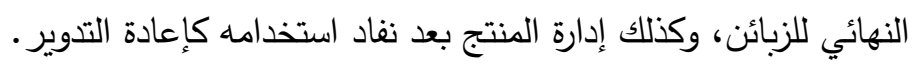


צ-بعد الإدارة البيئية أشار (Waxin et al., 2019, 495) إلى أنها عملية منهجية لتحسين أداء البيئة، من خلال دورة مستمرة لإدارة أنشطة المعمل التي يمكن أن يكون لها تأثير على البيئة، إذ يمكن لنظام الإدارة

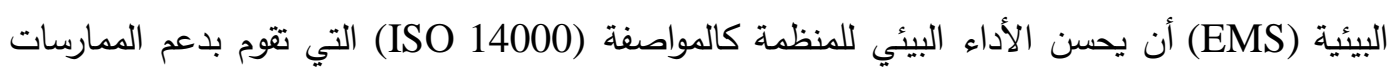

المبحث الثالث: الجانب الميداني

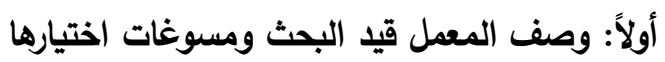

وقع الاختيار على معمل سمنت بادوش التابع للشركة العامة للسمنت الثمالية ميداناً للبحث، ويقع

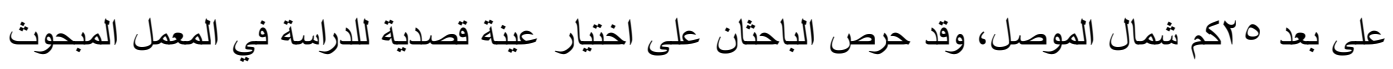

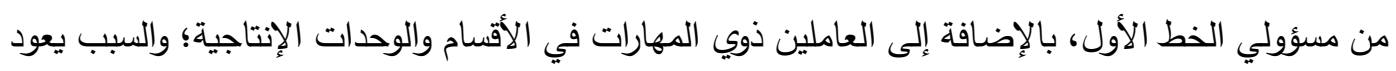

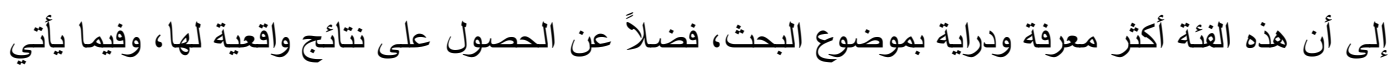

$$
\text { مجموعة من المسوغات لاختياره: }
$$

1-يتسم المعمل بخبرات ومهارات متراكمة لها دور في دعم الجانب الاقتصادي؛ وذلك لحاجة البلاد إلى مادة

ץ- الطلب على منتجاته من مادة السمنت بثكل مستمر ، وهذا يعني أن عملية الإنتاج لمادة السمنت مستمرة مصحوبة بالعديد من الملوثات التي تتتج عنها. r- رغبة الباحثين في المساهمة في تتمية وتطوير منظمات البلاد والنهوض بهات بهات

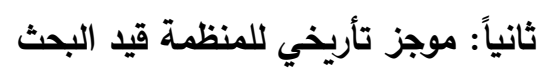
يتألف معمل سمنت بادوش من ثلاثة معامل أنثئت في ثلاثة أجيال، إذ يتمثل الجيل الاول في معمل سمنت بادوش القديم (جيل الخمسينيات) 1900 1907 1907 حيث يعمل بالطريقة الرطبة بفرنين وطاقة تصميمية

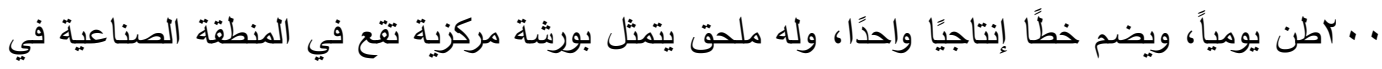

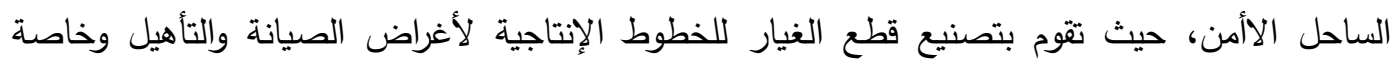
المسبوكات الفولاذية.

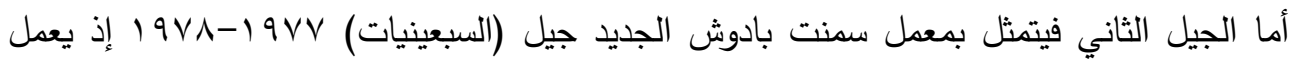

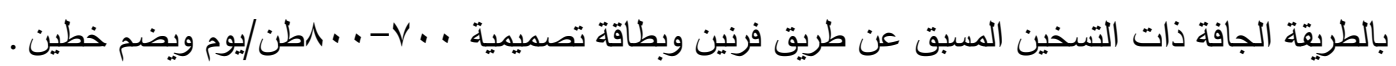

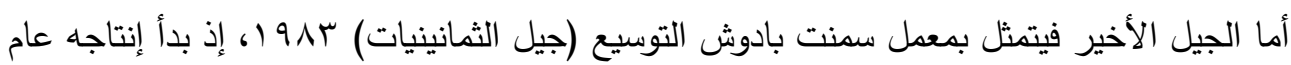

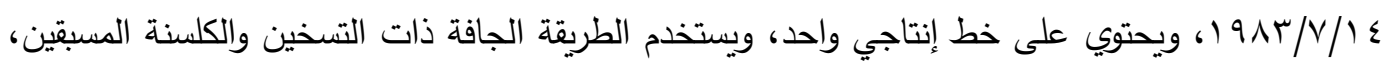

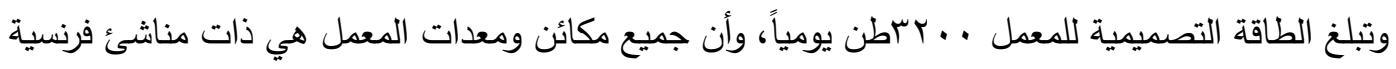
ويابانية. 
ثالثاً: وصف الأفراد المبحوثين

قام الباحثان بتوزيع (70) استمارة على الأفراد المبحوثين في المعمل قيد البحث، وتم الحصول على العثى

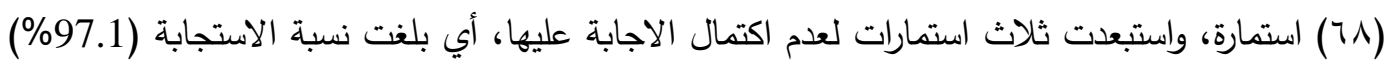

ويوضح الجدول أدناه تفاصيل توزيع هذه الاستمارات.

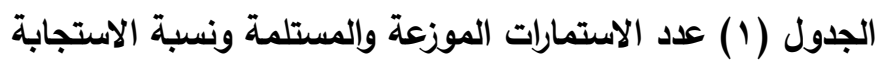

\begin{tabular}{|c|c|c|c|c|c|}
\hline نسبة & الصالحة & المستبعدة & نالاستجابة & المستلمة & الموزعة \\
\hline 92.9 & 65 & 3 & 97.1 & 68 & 70 \\
\hline
\end{tabular}

المصدر: من إعداد الباحثين بالاعتماد على نتائج الاستبانة.

الجدول (r) توزيع الافراد المبحوثين عينة البحث

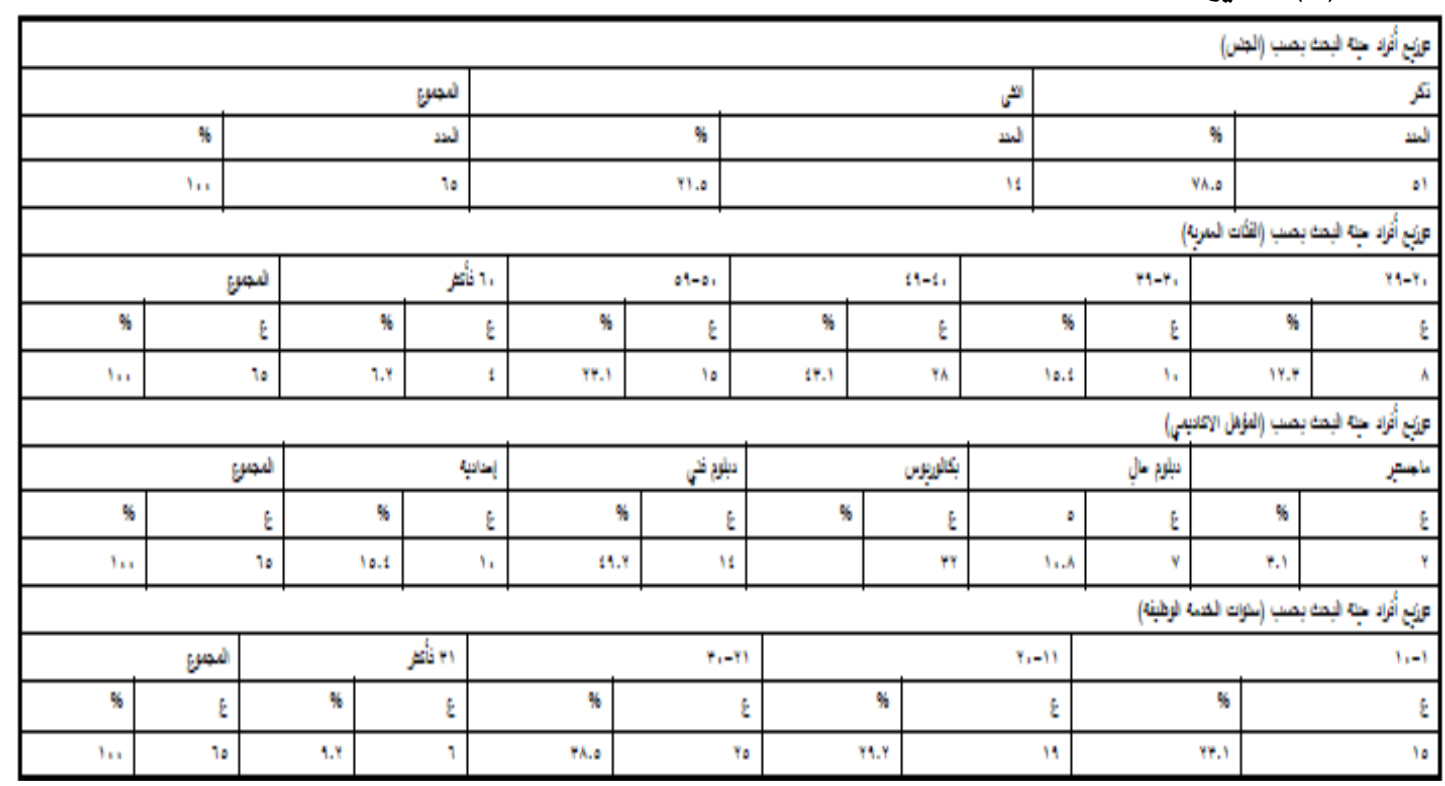

المصدر: من إعداد الباحثين بالاعتماد على نتائج الاستبانة.

رابعاً: علاقة الارتباط بين متطلبات التّفير التّنولوجي وأبعاد الإنتاج الأخضر مجتمعةً في المعمل قيد البحث: تم تخصيص هذا المحور للتحقق من قبول أو رفض (الفرضية الرئيسة الاولى) وعلى النحو الآتي:

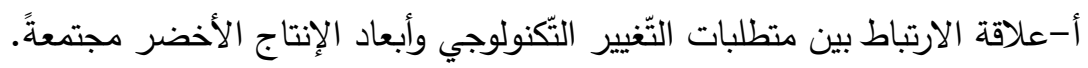

TANMIYAT AL-RAFIDAIN (P-ISSN: 1609-591X; E-ISSN: 2664-276X) تنمية الرافدين 
الجدول (َ) نتائج علاقة الارتباط بين متطلبات التَّيير التكنولوجي مجتمعة وأبعاد الإنتاج الأخضر مجتمعةً

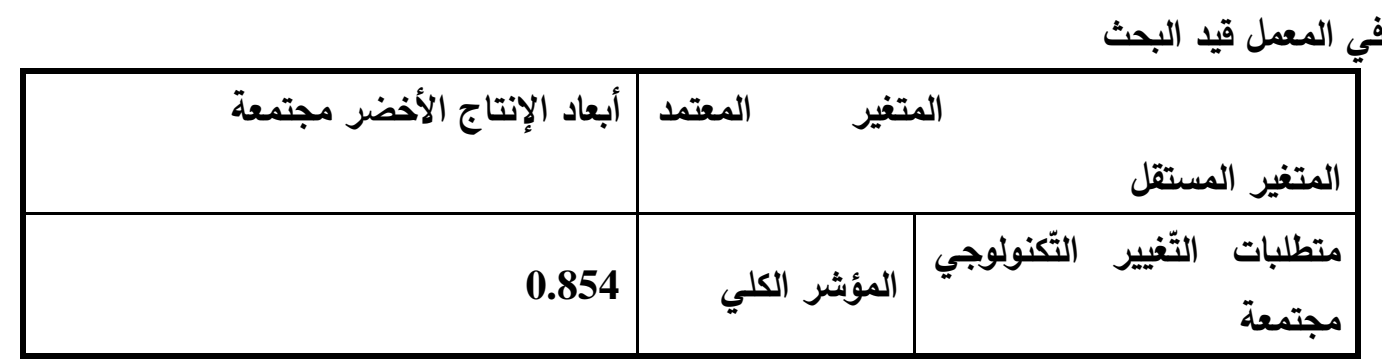

$\mathrm{P} \leq 0.05, \mathrm{~N}(1,57)$

$$
=65, \mathrm{df}=
$$

المصدر: من إعداد الباحثين بالاعتماد على نتائج برنامج

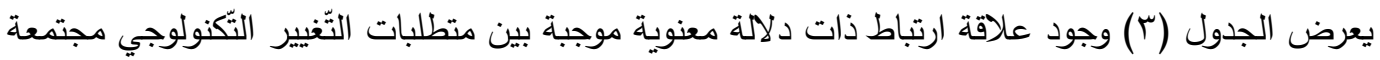

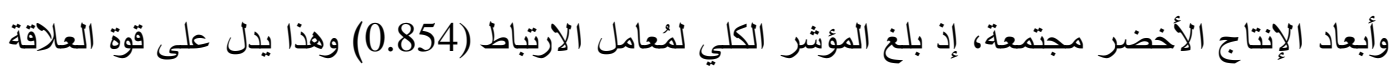

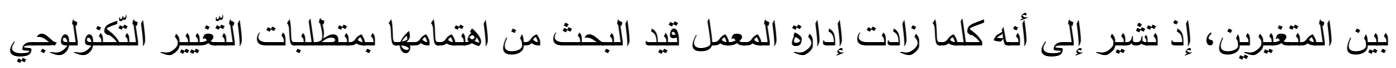

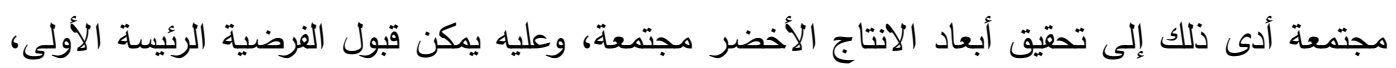

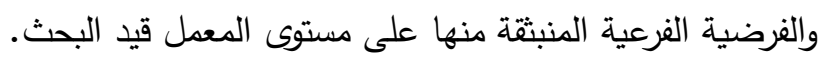
ب-علاقة الارتباط بين كل متطلب من متطلبات التّغيير التّكنولوجي المعتمدة في البحث وأبعاد الانتاج

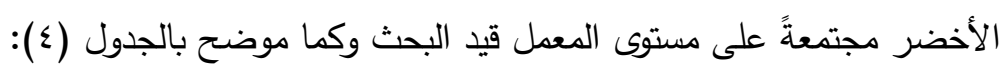
الجدول ( ) علاقة الارتباط بين كل متطلب من متطلبات التّفيير التّنولوجي وأبعاد الانتاج الأخضر مجتمعةً

\begin{tabular}{|c|c|c|}
\hline أبعاد الإنتاج الأخضر مجتمعة & \multicolumn{2}{|c|}{ المتغير المستقل } \\
\hline$\cdot, \wedge r v$ & البحث والتطوير & \multirow{4}{*}{ 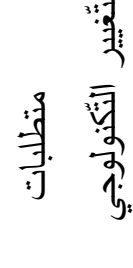 } \\
\hline$\cdot, T \cdot r$ & الابتكار التّكنولوجي & \\
\hline$\cdot, \wedge \leq 0$ & تكنولوجيا المعلومات & \\
\hline 0.805 & المؤشر الكلي & \\
\hline
\end{tabular}

$\mathrm{P} \leq 0.05, \mathrm{~N}=65, \mathrm{df}=(1,57)$

المصدر: من إعداد الباحثان بالاعتماد على نتائج برنامج SPSS

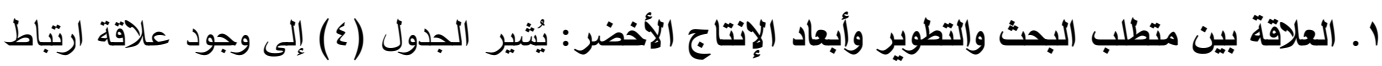

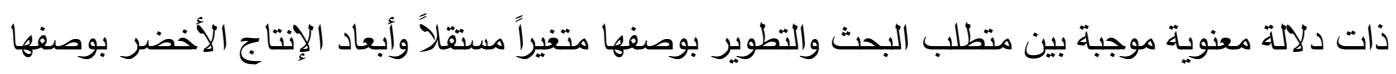
متغيراً معتمداً، إذ بلغت قيمة الارتباط (0.837) عند مستوى معنوية (0.05)، وتفسر هذه العلاقة أنه إذا قام

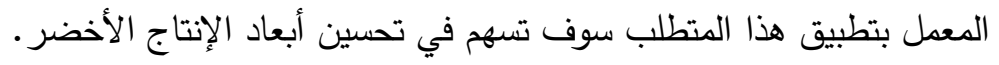

TANMIYAT AL-RAFIDAIN (P-ISSN: 1609-591X; E-ISSN: 2664-276X) تنمية الرافدين 
r. العلاقة بين متطلب الابتكار التّكنولوجي وأبعاد الإنتاج الأخضر : يُشير الجدول (ء) إلى وجود علاقة

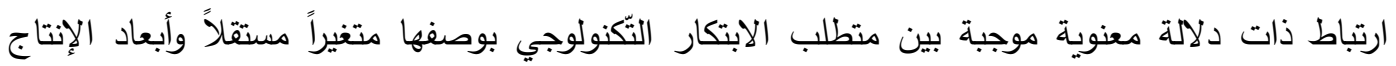

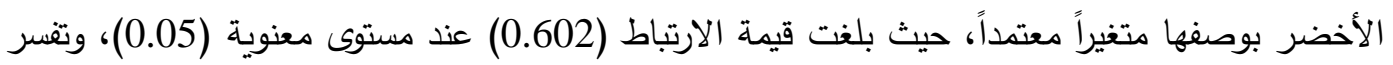
هذه العلاقة أنه إذا زاد اهتمام المعمل بتطبيق هذا المتطلب سوف تسهم في تحسين أبعاد الإنتاج الأخضر .

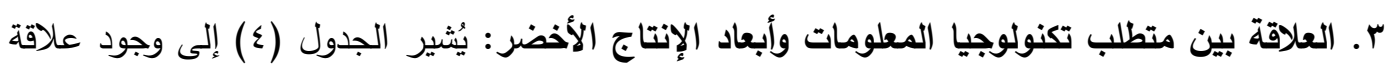

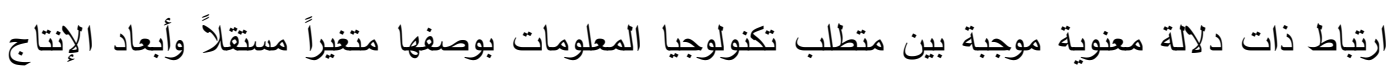

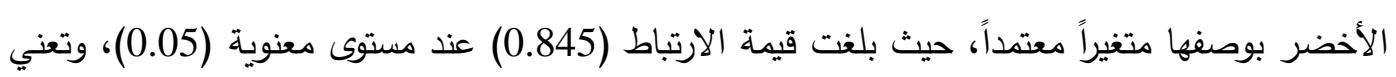
هذه العلاقة ما كان لاى المعمل من القدرة على تكنولوجيا المعلومات مما يُسهم ذلك في جعل تطبيق أبعاد

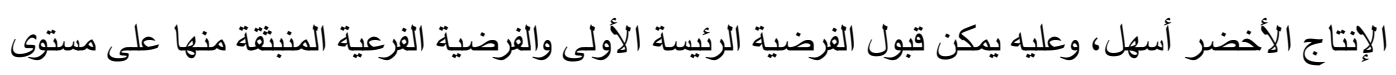

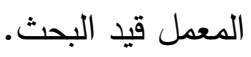
خامساً: علاقة التأثير بين متطلبات التّيير التّكنولوجي وأبعاد الإنتاج الأخضر مجتمعةً في المعمل قيد البحث:

تم تخصيص هذا المحور للتحقق من قبول أو رفض (الفرضية الرئيسة الثانية ) وعلى النحو الآتي:

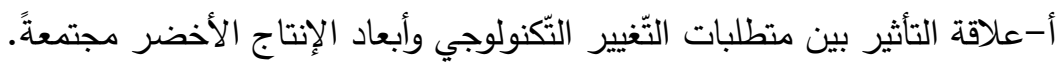

الجدول (ه) تأثير متطلبات التّفيير التكنولوجي مجتمعةً في أبعاد الإنتاج الأخضر مجتمعةً في المعمل قيد

\begin{tabular}{|c|c|c|c|c|c|c|}
\hline \multicolumn{2}{|c|}{ Fتبار F اخ } & \multirow[b]{2}{*}{$\mathrm{R}^{2}$} & \multicolumn{2}{|c|}{ متطلبات التّيير التكنولوجي } & \multirow{2}{*}{\multicolumn{2}{|c|}{ المتغير المستقل }} \\
\hline الجدولية & المحسوبة & & $\beta_{1}$ & $\beta_{0}$ & & \\
\hline$\varepsilon, \ldots \wedge$ & $1 \cdot 9,9 \cdot r$ & 0.654 & $0.510(10.483)^{*}$ & $\begin{array}{r}30.230 \\
(5.817)^{*}\end{array}$ & معاملات & 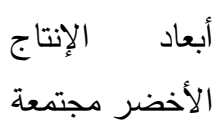 \\
\hline
\end{tabular}

$\mathrm{P} \leq 0.05 \mathrm{DF}=(5,53)$,

$$
\text { تثير (**) إلى T المحسوبة، T الجدولية= } 1.668
$$

, $\mathrm{N}=65$,

المصدر: من إعداد الباحثين بالاعتماد على نتائج برنامج SPSS

يتبين من الجدول (0) الخاص بنتائج تحليل الانحدار وجود تأثير معنوي موجب لاعتئ لمتغيرات متطلبات

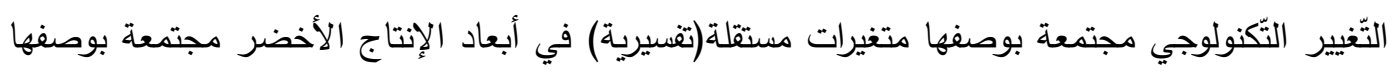

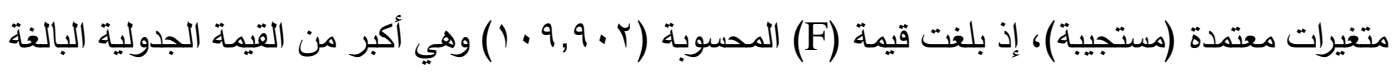

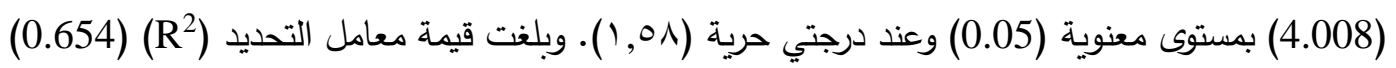
وهذا يعني أن (0.346) من الاختلافات المفسرة في أبعاد الإنتاج الأخضر مجتمعة تعود إلى تأثير متطلبات 
التّغيير التّكنولوجي مجتمعة، أما الباقي فيعود إلى متغيرات عشوائية من غير المكن السيطرة عليها أو أنها

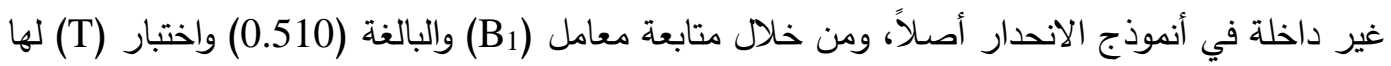
تبين أن قيمة (T) المحسوبة بلغت (10.483) وهي قيمة معنوية وأكبر من القيمة الجدولية البالغة (1.668) عند المستوى المعنوي (0.05) ودرجتي حرية (5,53)، وعليه يتم تقبل الفرضية الرئيسة الثانية والفرضية الفرعية المنبثقة منها على مستوى المعمل قيد البحث.

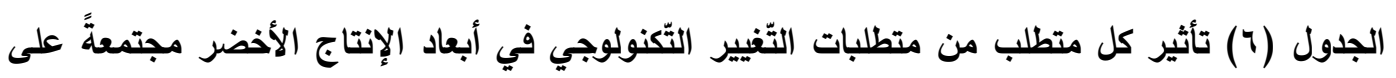

\begin{tabular}{|c|c|c|c|c|c|c|c|}
\hline \multicolumn{6}{|c|}{ متطلبات التّغيير التكنولوجي } & \multirow{3}{*}{ المستقل } & \multirow{3}{*}{ المتفير } \\
\hline \multicolumn{2}{|c|}{ تكنولوجيا المعلومات } & \multicolumn{2}{|c|}{ الابتكار التكنولوجي } & \multicolumn{2}{|c|}{ البحث والتطوير } & & \\
\hline$\beta_{3}$ & $\beta_{0}$ & $\beta_{2}$ & $\beta_{0}$ & $\beta_{1}$ & $\beta_{0}$ & & \\
\hline $\begin{array}{r}2.234 \\
(7.373)^{*}\end{array}$ & $\begin{array}{r}37.112 \\
(6.025)^{*}\end{array}$ & $\begin{array}{r}2.312 \\
(8.234)^{*}\end{array}$ & $\begin{array}{r}42.896 \\
(7.053)^{*}\end{array}$ & $\begin{array}{r}3.243 \\
(8.458)^{*}\end{array}$ & $\begin{array}{r}35.180 \\
(6.450)^{*}\end{array}$ & $\begin{array}{r}\text { قيم معاملات } \\
\beta\end{array}$ & \multirow{3}{*}{ 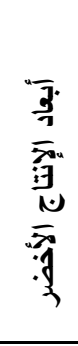 } \\
\hline & 0.473 & & 0.565 & & 0.564 & $\mathrm{R}^{2}$ & \\
\hline \multicolumn{2}{|r|}{ or, } & \multicolumn{2}{|r|}{ Tד, } & \multicolumn{2}{|r|}{$V_{0}, 1 \wedge V$} & إختبار F المسوبة & \\
\hline \multirow{2}{*}{\multicolumn{2}{|c|}{4.008}} & \multirow{2}{*}{\multicolumn{2}{|c|}{4.008}} & \multirow{2}{*}{\multicolumn{2}{|c|}{4.008}} & F Fتخبار F F F F & \\
\hline & & & & & & الجدولية & \\
\hline
\end{tabular}

$\mathrm{P} \leq 0.05 \quad \mathrm{DF}=(5,53)$,

تثير (**) إلى T المحسوبة، T الجدولية= 1.668 , $\mathrm{N}=65$,

المصدر: من إعداد الباحثان بالاعتماد على نتائج برنامج SPSS

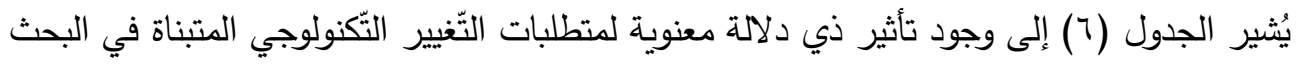
وهي ( متطلبات البحث والتطوير ، الابتكار التكنولوجي، تكنولوجيا المعلومات) بوصفها متغيرات مستقلة في دئي

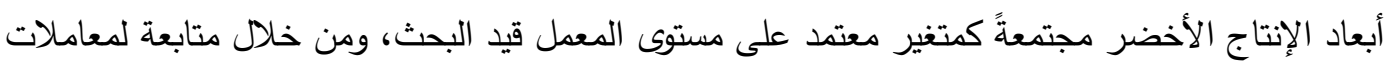

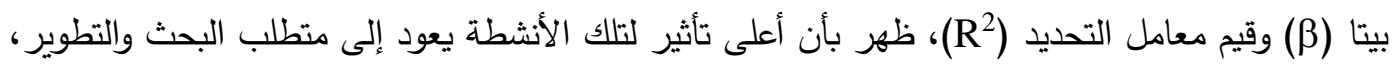
يليها بالدرجة الثانية متطلب الابتكار التّكنولوجي، ثم جاء تأثير متطلب تكنولوجيا المعلومات في النهاية، وفيما يأتي توضيح لتأثير كل متطلب من متطلبات التّغيير التّكنولوجي المتبناة في البحث وفق التئ الأولوية في تأثيرها في أبعاد الإنتاج الأخضر مجتمعةً. 1. تأثير متطلب البحث والتطوير في أبعاد الإنتاج الأخضر : يُبيّن الجدول (7) أن هناك تأثيراً معنوياً لمتطلب

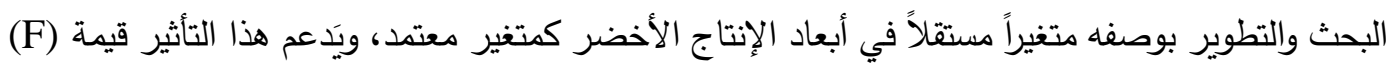

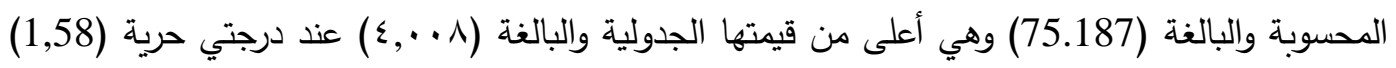


وضمن مستوى معنوية (0.05)، وبلغت قيمة معامل التحديد (R2) (0.564) وهذا يعني أن (0.436) من

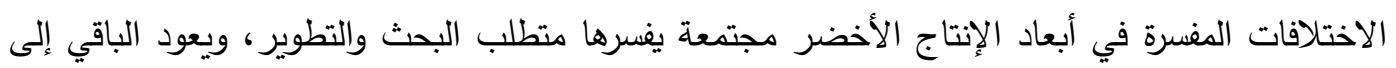
متغيرات عشوائية من غير الممكن السيطرة عليها أو أنها غير داخلة في أنموذج الانحدار أصلاً، وتبيّن أيضاً

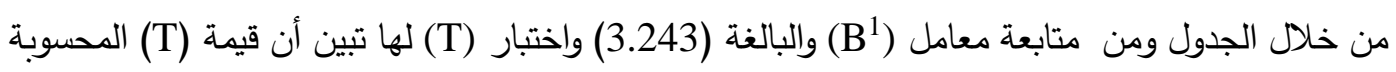
(8.458) وهي أعلى من قيمتها الجدولية والبالغة (1.568) (1.668) عند مستوى معنوية (0.05) ودرجتي حرية(5,53)، ونستتتج من هذا بأن متطلب البحث والتطوير لله قدرة في التأثير على أبعاد الإنتاج الأخضر مجتمعةً. r. تأثير متطلب الابتكار التّكنولوجي في أبعاد الإنتاج الأخضر يُبيّن الجدول (†) أن هناك تأثيراً معنوياً

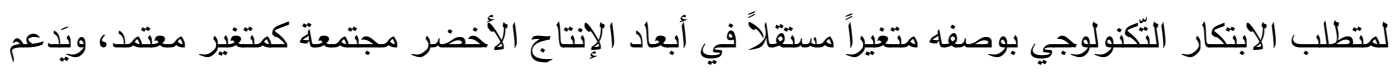

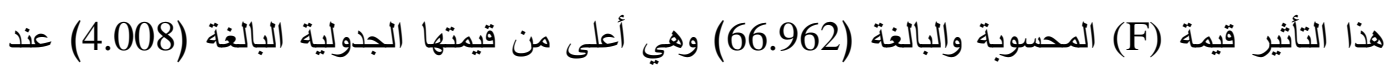

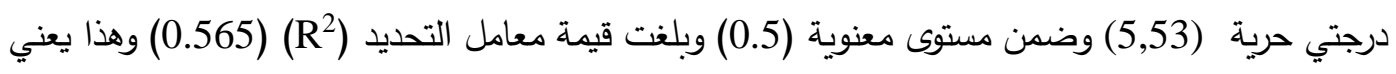

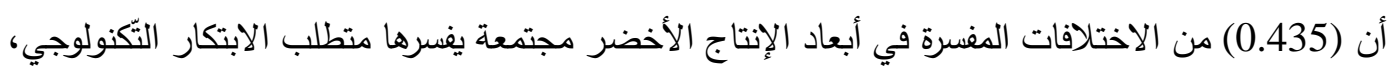

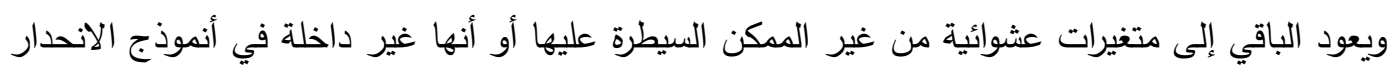

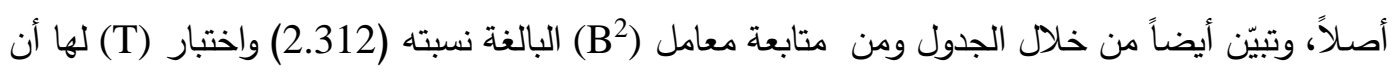

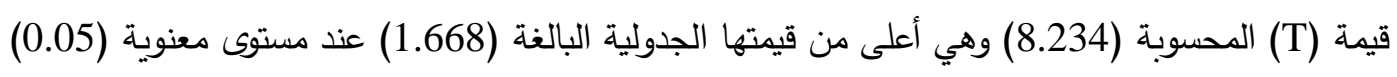
ودرجتي حرية (5,53)، ونستتنج من هذا إمكانية تأثير متطلب الابتكار التّكنولوجي في أبعاد الإنتاج الأخضر

r. تأثير متطلب تكنولوجيا المعلومات في أبعاد الإنتاج الأخضر : يُبيّن الجدول (؟) أن هناك تأثيراً معنوياً

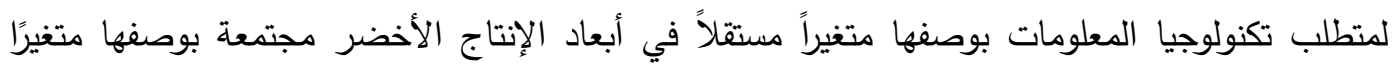
معتمدًا، ويَدعم هذا التأثير قيمة (F) المحسوبة والبالغة (53.065) وهي أعلى من قيمتها الجدولية البالغة

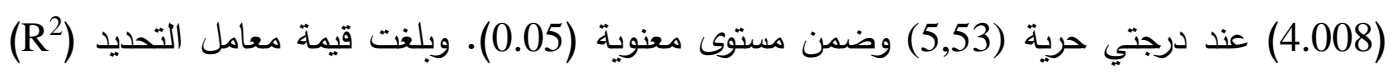

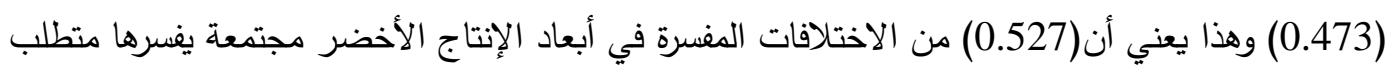

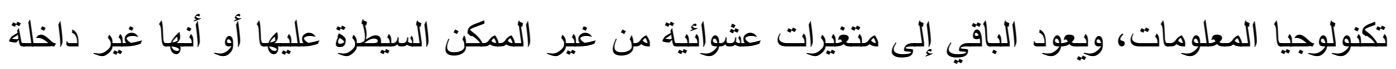

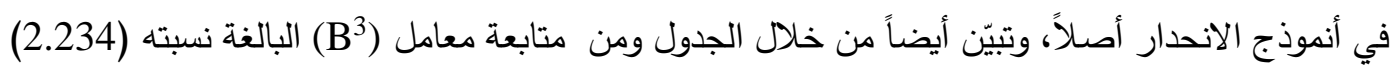

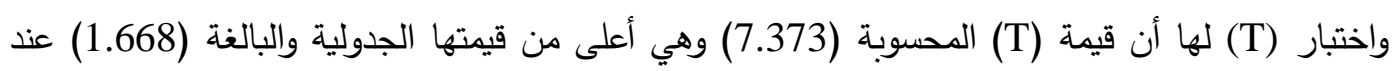
مستوى معنوية (0.05) ودرجتي حرية (5,53)، ونستتتج من هذا إمكانية متطلب تكنولوجيا المعلومات بالتأثير في أبعاد الإنتاج الأخضر مجتمعةً، وعليه يتم قبول الفرضية الرئيسة الثانية والفرضية الفرعية المنبثقة منها على مستوى المعمل قيد البحث.

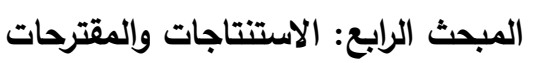
أولاً: الاستنتاجات 
ا ـ تحقق وجود علاقة ارتباط ذات دلالة معنوية بين متطلبات التّغيير التكنولوجي مجتمعةً وأبعاد الإنتاج الأخضر مجتمعةً في المعمل قيد البحث، وهذا يشير إلى أن زيادة دادة اهتمام إدارة المعمل بمتطلبات التّغيير

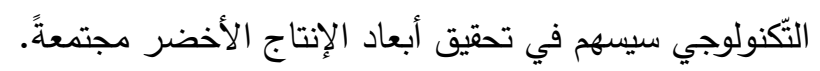
r. تحقق وجود علاقة ارتباط ذات دلالة معنوية بين متطلبات التّغيير التّكولوجي منفرداً وأبعاد الإنتاج

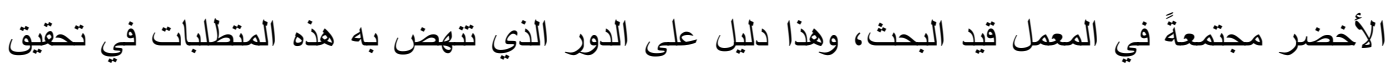

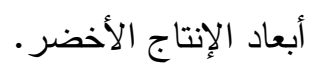
r. تحقق وجود علاقة تأثير ذات دلالة معنوية لمتطلبات التّغيير التكنولوجي في تحقيق أبعاد الإنتاج الأخضر في المعمل قيد البحث، وهذا يشير إلى إمكانية تأثير متطلبات التّغيير التكنولوجي في تحقيق أبعاد الإنتاج

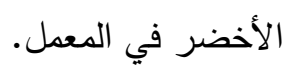
ء. ثبت وجود علاقة تأثير ذات دلالة معنوية لكل متطلب من متطلبات التّغيير التكنولوجي في تحقيق أبعاد الإنتاج الأخضر في المعمل قيد البحث، وهذا يشير إلى إمكانية تأثير كل متطلب من متطلبات التّغيير

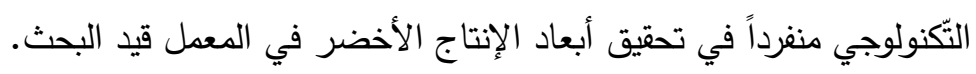
ثانياً: المقترحات ا ـ ضرورة الاهتمام بعمليات البحث والتطوير لما له من تأثير مهم وبارز في دعم التوجه نحو الإنتاج

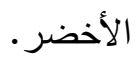
r. الحرص على استقطاب العاملين ممن يتسمون بالمهارة في مجال الابتكار التّكنولوجي، لما له من أهمية في تطبيق الإنتاج الأخضر عن طريق التتسيق مع الجامعات والمراكز العلمية المرموقة.

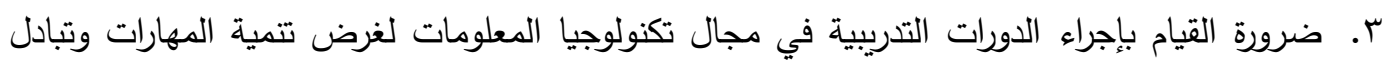
الأفكار بين العاملين. ـ. ت تركيز الاهتمام على الطاقة البديلة (الطاقة المتجددة) مثل الثمس والرياح وحرارة باطن الأرض وبخار الماء، إذ يمكن التوصّل إلى إنتاج مستدام من مادة سمنتية جديدة وصديقة للبيئة.

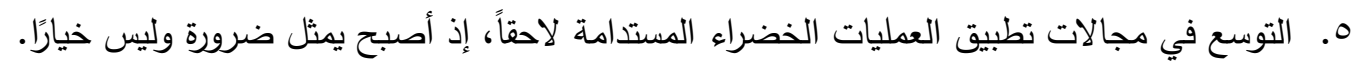

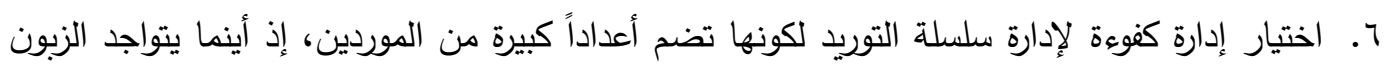

يكون مصدر توريد للمنظمة. V. . هنالك العديد من الأدوات لنظام الإدارة البيئية التي يمكن لإدارة المعمل قيد البحث استخدامها في مجال

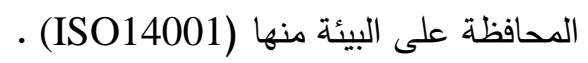

\section{References}

Abraham, Sherly Elizabeth, 2016, Information technology an enabler in corporate governance, journal of business in society, Vol. 12 ,No. 3.

Alsamydai, Mahmood Jasim, 2014, Adaptation of the Technology Acceptance Model (TAM) to the Use of Mobile Banking Services, International Review of Management and Business Research, Vol. 3, Issue.4. 
Aneirson, Francisco da Silva, Fernando, Augusto Silva Marins, Erica, Ximenes Dias \& Carlos, Alberto Ushizima , 2020, Improving manufacturing cycle efficiency through new multiple criteria data envelopment analysis models: an application in green and lean manufacturing processes, Production Planning \& Control, doi: 10.1080/09537287.2020.1713413.

Ansari, sajjad, 2016, sustainable operations management green way to industrial development, master thesis, master of technology, center for education technology, iit kharagpur, india.

Bakshi , Syed Murtuza Hussain ,2013, Information technology mangers role and responsibility A Study at Select Hospitals, Global journal of Computer and technology, Vol. 13, No.10, Osmania University, India.

Caliskan, hulya kesici , 2015 , technology change and economic growth, world conference on technology innovation, and entrepreneurship, university of Istanbul, baized fateh, istanbol, turkey.

Daft, Richard , 2010, Organization Theory and Design, Cengage Learning, USA .

Digalwar, Abhijeet, Mundra, Nidhi, Tagalpallewar, Ashok \& Sunnapwar Vivek, 2017, Road Map for The Implementation of Green Manufacturing Practices in Indian Manufacturing Industries An ISM approach, Benchmarking: An International Journal, Vol. 24,No 5, pp.1386-1399, doi: 10.1108/BIJ-082015-0084.

Ebhota, williams, 2014, engineering research and development economy (r\&d) infrastructure for developing, International journal of scientific \& technology research, Vol. 3, No, 4.

Godin, Benoit, 2015, Technological Change: What do Technology and Change stand for? Working Paper No.40, Project on the Intellectual History of Innovation, Montréal, Canada.

Huang J.-W., Li Y.-H., \& Yen M.-T., 2016. The Relationship between Green Innovation and Business Performance-The Mediating Effect of Brand Image, Sansia, Vol. 13, No. 1.

Khin S., Ahmad N.H. \& Ramayah T. ,2010, Product innovation among ICT technopreneurs in Malaysia, Business Strategy Series, Vol.11, No.6.

Lokpriya, Gaikwad \& Sunnapwar, Vivek , 2020, The Role of Lean Manufacturing Practices in Greener Production: A Way to Reach Sustainability, International Journal of Industrial and Manufacturing Systems Engineering, Vol. 5, No. 1, doi: 10.11648/j.ijimse.20200501.11.

Lvens , bjorn, 2012, organizational adaptation to discontinuous technological change, nadin kummerlanderst, gallen, switzeland dissertation , university of bamberg 2012.

Machado C., Winroth M. \& Silva E., 2019, Sustainable manufacturing in Industry 4.0: an emerging research agenda, International Journal of Production Research, Vol. 58, No. 5, doi:10.1080/00207543.2019.16 52777.

TANMIYAT AL-RAFIDAIN (P-ISSN: 1609-591X; E-ISSN: 2664-276X) تنمية الرافدين 
Nikoloski, krume, 2016 , technology and economic development: retrospective , journal of process management-new technologies, international Vol. 4, No.4, goce delchev university, macedonia, doi: / 1 •, ०9 rvjouproman411468 .

Petljak, K., Zulauf, K., Štulec, I., Seuring, S. \& Wagner, R., 2018, Green supply chain management in food retailing: survey-based evidence in Croatia , Supply Chain Management, Vol. 23 No. 1, https:// doi.org/10.1108/SCM04-2017-0133.

Ruben Dewitte, Michel Dumont, Bruno Merlevede, Glenn Rayp \& Marijn Verschelde, 2019, Firm-Heterogeneous Biased Technological Change: A nonparamet-ric approach under endogeneity, European Journal of Operational Research Vol.11, No. 63, doi.org/10.1016/j.ejor.2019.11.0 63

Sen ,Prakash K., Bohidar Shailendra K., Shrivas Yagyanarayan, Sharma Chandan. \& Modi Vivek, 2015, Study On Innovation Research And Recent Development In Technology For Green Manufacturing, International Journal Mechanical Engineering and Robotics Research, Vol. 4, No. 1.

Sen, Saurabh \& Ruchi, L. Sen, 2020, Green Manufacturing: The Need of the Hour for Developing Nations- A Case Study In I. Management Association (Ed.), Waste Management: Concepts, Methodologies, Tools, and Applications, Hershey, PA: IGI Global.

Stoever J., \& Weche J. P., 2018, Environmental regulation and sustainable competitiveness: Evaluating the role of firm-level green investments in the context of the Porter hypothesis, Environmental and Resource Economics, Vol.70, No.2, doi.org/10.1007/ s10640-0 17 -01

Ulrich , Doraszelski \& Jordi, Jaumandreu , 2018, Measuring the bias of technological change ,Journal of Political Economy, Vol. 126, No. 3 ,The University of Chicago. All rights reserved. 0022-3808.

Wang, Xianlin, Chen, Le, Dan , Binbin \& Wang, Fei , 2018 , Evaluation of EDM process for green manufacturing, The International Journal of Advanced Manufacturing Technology, Vol. 94, doi 10.1007/s00170-0170892-y.

Waxin, M., Knuteson S. \& Bartholomew A., 2019, Drivers and challenges for implementing ISO 14001 environmental management systems in an emerging Gulf Arab country, Environmental Management, Vol. 63, Doi: 10.1007/s00267-017-0958-5.

Xiaodong, Li \& Hengli, Liu ,2016 , Research and Application on Green Manufacturing in Industrial Design, Key Engineering Materials, Vol. 693, doi:10.4028/www.scientific.net/kem.693.2003.

Ganzer, Paula Patricia, Chais, Cassiane \& Olea, Pelayo Munhoz, 2017, Product Process Marketing and Organizational Innovation in Industries of the Flat Knitting Sector, Science Direct Journal, Vol. 14.

TANMIYAT AL-RAFIDAIN (P-ISSN: 1609-591X; E-ISSN: 2664-276X) تنمية الرافدين 
متطلبات التّغيير التّكنولوجى على وفق أبعاد

يوسف والجليلي

TANMIYAT AL-RAFIDAIN (P-ISSN: 1609-591X; E-ISSN: 2664-276X) تنمية الرافدين 